\title{
Challenge based learning: a real-world approach for secondary students to solve complex problems using geoscience knowledge and skills
}

\author{
B. NICHOLLS \\ Adelaide Botanic High School. c/- Department for Education, South Australa 5000. E-mall: Slab@internode.on.net
}

Abstract: Students are regularly confronted with ethical and environmental issues of a global, regional or local nature which require knowledge of the geosciences to solve. Having the skills to engage, explore and evaluate these problems enhances student's capacity for creative, real-world problem solving. At the Australian Science and Mathematics School, a Challenge Based Learning approach has been used across a range of learning programs including those with a focus on geoscience. Challenge Based Learning in the context of this paper is defined as a method of teaching and learning which allows students to engage in learning goals through meaningful contexts. An unfamiliar 'ill-structured' problem is presented to the students by the teacher and the students are required to determine for themselves how they will go about solving the problem. This process occurs through small groups of students working collaboratively and allows sharing their prior knowledge, skills and understandings to identify gaps in their collective understanding as they attempt to offer solutions to the problem. The example chosen is based around a problem requiring significant time in the field where secondary students come to know and understand the problem in greater depth while developing scientific field investigation skills.

\section{Manuscript:}

Received: Quadrennial Conference of the International Geoscience Education Organization

Accepted: 14/01/2018

Citation: Nicholls B. 2018. Challenge based learning: a real-world approach for secondary students to solve complex problems using geoscience knowledge and skills. Terræ Didatica, 14(4):369-372. URL: http://www. ige.unicamp.br/terraedidatica/.

Keywords: Fieldwork, secondary school, real-world

Thematic line: Education, Teaching of Geosciences and Teacher Training.

\section{Introduction}

Over recent years, Problem-based Learning (PBL) has gained popularity with teachers in high schools due to its potential to increase student engagement through using realistic problems in conjunction with collaborative problem-solving thus increasing student's ownership of learning. The push in many school systems for students to develop real-world competencies or capabilities for future careers is also driving change in classroom practice. At the Australian Science and Mathematics School (ASMS) the PBL process has been refined to Challenge Based Learning (CBL) to reflect 'productive struggle'. Struggle occurs when a student approaches a task or problem that initially seems beyond their capability; for which there is no clear path to a solution and that is challenging but is within the student's reach (Hiebert \& Wearne, 2003). Student's control their learning with teachers acting as guides or mentors who connect them with possible resources and come to construct new knowledge through prob- lem solving and collaborating with others. In the example in this paper, a CBL approach was used in a field learning context with the potential to deepen students understanding of the complexity of the natural world.

CBL contrasts with traditional didactic methods which provide students with the required theoretical knowledge through the teacher controlling the content and restricting the role of students in the learning process. This approach may lead to a lower cognitive demand of the student as tasks become routine, sending a message of 'only one correct way' by specifying procedures, shifting learning from concepts and understanding to correctness or completeness.

\section{Design and Implementation of CBL style learning}

The role of the teacher in PBL needs clarification. Some advocates of PBL style pedagogies claim there is no need for content expertise, even 
claiming that PBL can be facilitated by non-discipline experts so long as they are trained in PBL facilitation skills. Seng (2004) argues that such assumptions will prepare a generation of superficial learners. The acquisition of problem solving skills, depth of disciplinary inquiry and discipline related skills are important for tackling the challenges of the knowledge-based area. However, a discipline expert may be limited in implementing PBL if they do not understand their role and lack coaching skills, such as how to respond to questions and guide students through the stages of the PBL cycle. For a PBL approach to be successful, a balance of teacher skill and knowledge is required. So, there are important issues to consider before launching into PBL.

The initial design phase began many months before the CBL, primarily because a field trip was involved. In this case, the field camps were linked to a semester unit, Sustainable Futures and students selected from a range of options with some close to the school and involved day trips, whereas others included one to four overnight stays. The teacher chose a relevant challenge of worth which was strongly connected to the curriculum and also determined the base of discipline knowledge and skills the students required to understand the challenge. The CBL learning program was developed and built into a teaching and learning plan meeting the learning intentions of the Sustainable Futures curriculum. The second phase, implementation, was when the students were presented with the challenge and began to follow through the steps in the model presented in figure 1 based on the Illinois Maths and Science Academy (IMSA) 2009 PBL model. The teacher decided on critical teaching and learning events and embedded assessments (both formative and summative) with appropriate instruction.

\section{A Field-based CBL with an extended field}

\subsection{Understand the challenge}

All the students studying the Sustainable Futures course were involved in CBL. The preparations involved many in-class activities specific to the field camp they had chosen. Before the field camp, the teacher set the scene by providing the problem: "Should the Mound Spring ecosystems of the Western Great Artesian Basin be protected".

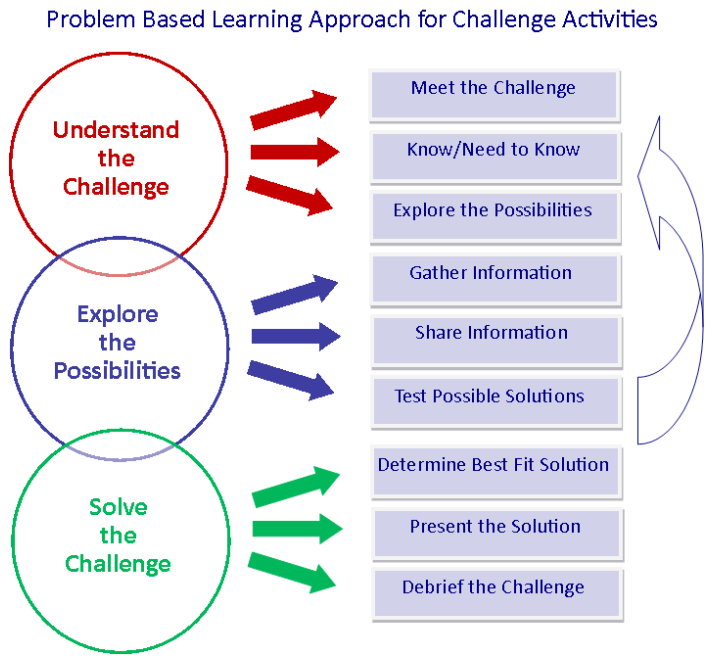

Figure 1. Summary of the Challenge Based Learning process

Students were given an opportunity to develop the skills they would need by learning how to use water monitoring equipment in a local pond. They worked through a series of field tests and were encouraged to ask the teacher clarifying questions. For the knowledge component, students attended a presentation from a hydrogeologist who has conducted field investigations in the Mound Springs region for the past 10 years. This area of South Australia is quite remote and none of the students had visited the area or had prior knowledge of the springs. He provided extensive notes and resources on the geology, geomorphology, ecology and hydrology of the region and an easy to understand summary of the lifecycle of a mound spring.

Students then formed collaborative research teams based on their interest, where they shared what they knew. In these teams, they developed sub-questions they would explore in the field, such as: "Should future expansions of the Olympic Dam Mine operations continue to draw water from the Great Artesian Basin?"

During this process, they designed their field investigations such as; measuring and calculating spring flow, observation of Mound formation, analysis of sediment composition, distribution and abundance of aquatic macro-organisms and aquatic micro-organisms and physical and chemical properties of the spring water.

Once the students had an idea of the problem and ways they could investigate features of the Mound Springs, they collaborated with the teacher to collect a range of equipment to construct their 
own field measurement and recording instruments. They also discussed in their team what other information and skills they needed prior to conducting their investigation.

\subsection{Explore the possibilities in the field}

During the information gathering stage, the students participated in a tour of the Olympic Dam mining operation and visited the township that supports the mine, Roxby Downs, where they gained a deeper appreciation of the water requirements for the mine and town. After the tour, the students travelled to the campsite near the field investigation location and set up camp. Once they had explored the Mound Springs, they refined their statement and investigation based on the local conditions and accessibility to the site. They also had great fun constructing their scientific instruments, learning to improvise with the materials they had packed. Their investigation proposals were modified ready for approval by the teacher. The teacher then provided considerable feedback which they used to modify and improve their experimental design.

In their groups, the students conducted their investigation, collecting data for sharing with the whole class. During this sharing process, they sought further information to clarify their understanding of the problem allowing them to suggest viable solutions. Some groups chose to modify their sub-question after considering the shared data.

\subsection{Solve the challenge}

In the final stage, students generated possible solutions, with each team framing a response to their sub-question based on their own field investigation and other research. Each team shared the key information from their own field investigation with a poster presentation and discussion. The whole team then discussed the range of options proposed as the 'best fit' solution to the original problem. Through discussion and careful analysis of all the evidence from the field and other sources, agreement on the most appropriate solution for the problem was reached.

For the process to have meaning for the individual, each student considered what further personal action they could take. For most, being in a new environment, bush camping and simply being away from home were great challenges. Exploring future study in areas such as geoscience, hydrol- ogy and archaeology became a focus for those who enjoyed the experience and wanted to know how they could pursue a career in these areas.

The personal reflections below express the experiences of three students.

A challenge for me is that I have never camped before and therefore, did not know much about how I was going to manage the task. (Year 10 female student)

During the field trip I had brought equipment that allowed for me to take notes on the sites visited and document the main ideas. I found that if I actively participated in all the stops and activities there were, I would be able to conduct the experiment well and also learn a great amount from the guides, teachers and also people who lived at the sites. Listening to the different perspectives proved to be very useful." (Year 10 male student)

The major challenge of this task was to collect samples of water in an unfamiliar environment with unknown variables. This process was time consuming and required a great amount thinking to predict the variables that can affect the process of the investigation. (Year 11 female student)

The learning situation outlined above explains how students were challenged to suggest solutions to problems they were confronted with during the field experience, identify ethical questions and the implications inherent in making public policy decisions about controversial geoscience issues involving mining. The students developed geological field work skills through the design and manipulation of scientific equipment, making accurate field observations and measurements, recording them and presenting these in an appropriate format.

\section{Conclusion}

The students involved in the Mound Springs field camp had experienced CBL in other formats, including within a learning program, where two 100-minute sessions per week for 10 weeks was set aside for the CBL activity.

Another format was in a learning program which occurred during the annual ASMS International Science Fair, where a week was devoted to a CBL activity. Together with visiting international students, they nominated a Challenge from a broad selection of options around the theme of the Science Fair. Anecdotal feedback from students 
indicate they preferred the 5-day field camp model where they had time to consider the problem, where immersed in the context of the problem and collaborated in an unfamiliar setting.

The focus on student-centred learning, with students making decisions about their learning and the teacher taking on a support role provided students with greater sense of ownership of their learning and hence higher levels of engagement.

\section{References}

Hiebert J., Wearne D. 2003. Developing understanding through problem solving. In H.L. Schoen, R.I. Charles eds. 2003. Teaching mathematics through problem solving: Grades 6-12. Reston, VA: NCTM.

Tan O.S. 2004. Editorial. Special issue: Challenges of problem-based learning. Innovations in Education and Teaching International, 41(2):123-124. 